\title{
DNA metabarcoding reveals changes in the contents of carnivorous plants along an elevation gradient
}

\author{
Joanne E. Littlefair ${ }^{1,2}$ | $\mid$ Axel Zander ${ }^{3}$ | Clara de Sena Costa ${ }^{2}$ | Elizabeth L. Clare ${ }^{2}$ (D)
}

${ }^{1}$ Department of Biology, McGill University, Montréal, Québec, Canada

${ }^{2}$ School of Biological and Chemical Sciences, Queen Mary University of London, London, UK

${ }^{3}$ Department of Biology, Unit of Ecology and Evolution, University of Fribourg, Fribourg, Switzerland

\section{Correspondence}

Joanne E. Littlefair, Department of Biology, McGill University, Montréal, Québec,

Canada.

Email: j.e.littlefair@gmail.com

\section{Funding information}

Schweizerischer Nationalfonds zur Förderung der Wissenschaftlichen Forschung, Grant/Award Number: 31003A_138489

\begin{abstract}
Resource variation along abiotic gradients influences subsequent trophic interactions and these effects can be transmitted through entire food webs. Interactions along abiotic gradients can provide clues as to how organisms will face changing environmental conditions, such as future range shifts. However, it is challenging to find replicated systems to study these effects. Phytotelmata, such as those found in carnivorous plants, are isolated aquatic communities and thus form a good model for the study of replicated food webs. Due to the degraded nature of the prey, molecular techniques provide a useful tool to study these communities. We studied the pitcher plant Sarracenia purpurea $L$. in allochthonous populations along an elevational gradient in the Alps and Jura. We predicted that invertebrate richness in the contents of the pitcher plants would decrease with increasing elevation, reflecting harsher environmental conditions. Using metabarcoding of the COI gene, we sequenced the invertebrate contents of these pitcher plants. We assigned Molecular Operational Taxonomic Units at ordinal level as well as recovering species-level data. We found small but significant changes in community composition with elevation. These recovered sequences could belong to invertebrate prey, rotifer inquilines, pollinators and other animals possibly living inside the pitchers. However, we found no directional trend or site-based differences in MOTU richness with elevational gradient. Use of molecular techniques for dietary or contents analysis is a powerful way to examine numerous degraded samples, although factors such as DNA persistence and the relationship with species presence still have to be completely determined.
\end{abstract}

\section{KEYWORDS}

carnivory, DNA metabarcoding, food web, invasive, molecular dietary analysis, plant-insect interactions, Sarracenia purpurea

\section{1 | INTRODUCTION}

Spatial and temporal variation in resource distribution is present throughout an organism's environment. Environmental resources and stressors may be organized in a spatial hierarchy or along a gradient, as is the case for heat stress and elevation, or pressure and ocean depth (Desmarais \& Tessier, 1999; Flesch \& Steidl, 2010; Jones,
Baltz, \& Allen, 2002; O'Gorman et al., 2012). Studies of how resource use varies along environmental gradients are likely to be important for understanding species invasions (Gallien et al., 2015), and responses to climate change scenarios as species undergo range shifts (Colwell, Brehm, Cardelus, Gilman, \& Longino, 2008; Parmesan, 2006). Gradients can also serve as natural experiments to extrapolate the temporal variability of communities and ecosystems 
(Fukami \& Wardle, 2005; Lester, Close, Barton, Pope, \& Brown, 2014).

Elevation is one source of variation in resource distribution. Resources alter either as a direct result of abiotic factors or from the effects of abiotic factors on biotic components. Abiotic conditions vary with elevation: higher altitudes are strongly associated with exposure to colder temperatures (known as the lapse rate), more extreme weather patterns, greater exposure to UV, lower atmospheric pressure and lower oxygen availability (Blumthaler, 2012; Hodkinson, 2005). Common biotic responses include shifts in species distribution, or complete species replacement, as organisms differ in their environmental tolerances (e.g., thermal limits Sundqvist, Sanders, \& Wardle, 2013). Although it was initially thought that biodiversity decreases with increasing elevation, Rahbek (2005) demonstrated a peak in diversity at midelevation, which holds true for $75 \%$ of elevational gradients examined (Rahbek, 2005; Sundqvist et al., 2013), although different functional groups will vary in their response (Sundqvist et al., 2013).

When gradients influence species distributions, we expect variation in trophic relationships within ecosystems. For example, the change in biodiversity with elevation will influence predator-prey and host-parasite interactions (Case, Holt, Mcpeek, \& Keitt, 2005). This is difficult to study on a spatially replicated scale in the field, although attempts have been made experimentally (Greig, Wissinger, \& Mcintosh, 2013). Phytotelmata are isolated aquatic communities that form natural mesocosms in living terrestrial plants, such as bromeliads, tree holes and certain types of carnivorous plant (Kitching, 2000), and can be studied as small replicated ecosystems located within a larger landscape (Kitching, 2000).

The leaves of pitcher plants form phytotelmata, connecting the external environment to an enclosed aquatic food web of inquilines that aid in the decomposition of invertebrate prey. Prey are sources of nitrogen and phosphorus, which compensate for the nutrient-poor environments which the pitcher plants inhabit. Prey capture has been shown to increase plant fitness (Zamora, Gomez, \& Hodar, 1997), and the inquiline food web is limited by prey capture (Heard, 1994). Unlike bromeliads or tree holes, which are primarily containers, pitcher plants are an active part of the phytotelmata ecosystem. While obtaining nutrients is crucial for both plant and inquiline biology, it is not known to what extent the invertebrate contents of pitcher plants are shaped by gradients such as elevation which can structure resources. Here, we test the ecological hypothesis that pitcher plant phytotelmata contents are influenced by elevational gradients.

The morphological identification of prey is often complicated by digestion and degradation. This problem has been encountered both generally (Pompanon et al., 2012; Valentini et al., 2009), and specifically in pitcher plants, where studies refer to an unidentified mass of insect exoskeletons (Cresswell, 1991; Horner, Steele, Underwood, \& Lingamfelter, 2012). Additionally, the characterization of food webs involving generalist predators of insects has so far been beyond the reach of most attempts, due to the huge numbers of links made with prey species (Clare, 2014; Pompanon et al., 2012). Sequencing technologies such as metabarcoding, the massively parallel sequencing of targeted gene fragments from all components of an environmental sample, are now commonly used to analyse the partially digested elements of diet. Metabarcoding is fast becoming the tool of choice in dietary analyses, including work on a wide range of diet types such as liquids (sap, blood, nectar, etc.), prey which do not leave hard remains or where destructive sampling is not ethical, or the material highly degraded (Clare, 2014; Pompanon et al., 2012). Clustering sequences into Molecular Operational Taxonomic Units (мотU) (Floyd, Abebe, Papert, \& Blaxter, 2002) can be used to quantify diversity for subsequent ecological analyses (Clare, Chain, Littlefair, \& Cristescu, 2016).

In this study, we examine how the invertebrate contents of a carnivorous pitcher plant (Sarracenia purpurea) alter over an elevational gradient. The natural range of $S$. purpurea extends from Florida to subarctic Canada, in nutrient-limited areas (Kneitel \& Miller, 2002). However, S. purpurea has been frequently introduced in Britain, Ireland and central Europe from escaped ornamentals and deliberate planting in bog areas, and displays invasive characteristics in certain areas of central Europe due to its frost-hardy nature (Adlassnig, Mayer, Peroutka, Pois, \& Lichtsheidl, 2010; Walker, 2014; Zander, Gravel, Bersier, \& Gray, 2016). Sarracenia purpurea is a particularly interesting case for the study of elevation gradients as the plant is allochthonous in the Alps, and thus, it has not undergone long-term adaptation to the environment. As such, we can assess resource variation induced by elevational gradients against a background of species invasion.

In this study, we use DNA metabarcoding techniques to investigate the contents of Sarracenia purpurea across sites in France and Switzerland over an elevation gradient of $850 \mathrm{~m}$. We assess how MOTU richness and community composition of invertebrate contents of pitcher plants changes with elevation, and test for linear and other relationships between elevation gradient and MOTU richness. Finally, we predict that community dissimilarity will vary in such a way that the most similar communities are closer in elevation to each other.

\section{2 | MATERIALS AND METHODS}

\section{1 | Sample collection}

We collected samples of pitcher contents from Sarracenia purpurea pitchers in five locations in the Alps, Jura Mountains and the Swiss Plateau (Switzerland and France), between October 29 and November 28, 2014. Our sampling locations comprised of raised bogs, fens and alpine wetlands at Champ Buet $\left(46^{\circ} 36^{\prime} 41^{\prime \prime} \mathrm{N} 6^{\circ} 34^{\prime} 41^{\prime \prime} \mathrm{E}\right.$, ca. $600 \mathrm{~m}$ a.s.l), Frasne $\left(46^{\circ} 49^{\prime} 35^{\prime \prime} \mathrm{N} \mathrm{6} 6^{\circ} 10^{\prime} 25^{\prime \prime} \mathrm{E}\right.$, ca. $800 \mathrm{~m}$ a.s.l), Les Embreux $\left(47^{\circ} 15^{\prime} 44^{\prime \prime} \mathrm{N} 7^{\circ} 6^{\prime} 57^{\prime \prime} \mathrm{E}\right.$, ca. $1000 \mathrm{~m}$ a.s.l), Les Tenasses $\left(46^{\circ} 29^{\prime} 28.37^{\prime \prime} \mathrm{N} 6^{\circ} 55^{\prime} 15.00^{\prime \prime} \mathrm{E}\right.$, ca. $1200 \mathrm{~m}$ a.s.l) and Les Mosses $\left(46^{\circ} 23^{\prime} 47.10^{\prime \prime} \mathrm{N}, 7^{\circ} 5^{\prime} 59.79^{\prime \prime} \mathrm{E}\right.$, ca. $1450 \mathrm{~m}$ a.s.l). (NB: Full grid coordinates will be given to interested members of the scientific community by the corresponding author.) We downloaded temperature and rainfall data from bioclim for these sites at $1-\mathrm{km}^{2}$ resolution (Fick \& 
Hijmans, 2017) to characterize the sites, and these data are presented in Supporting information Table S1. Because these plants are confined to bog sites, a true continuous gradient is not possible, and thus we attempted to spread collections across even elevational increases. Additionally, we assumed that phylogenetic relationships amongst plant populations at different altitudes did not directly influence their contents. We collected at least 40 pitcher plant leaves at each site, except at $800 \mathrm{~m}$ where we could only collect 25 , because fewer plants were available there. We targeted our collection to undamaged pitchers of a similar size and age from a mixture of clumps of S. purpurea within each site. We visually inspected the contents of each pitcher for living organisms and found none. We transferred the contents of each pitcher leaf with autoclaved cut-off pipette tips into a sterile $50-\mathrm{ml}$ macrocentrifuge tube (Zander et al., 2016) and froze these at $-20^{\circ} \mathrm{C}$ for molecular analysis.

\section{2 | Molecular techniques}

Prior to extraction, we dried the samples for $48 \mathrm{hr}$ at $40^{\circ} \mathrm{C}$ in a Heratherm oven (Thermo Scientific). We extracted DNA using a Qiagen Blood and Tissue kit (Qiagen, UK), with some modifications to the protocol as follows. We added enough ATL buffer to cover the entire sample and then incubated these at $56^{\circ} \mathrm{C}$ for $48 \mathrm{hr}$ with shaking to mix the contents. We then transferred $180 \mu \mathrm{l}$ of liquid from this material to a 2-ml Eppendorf tube with $20 \mu$ proteinase K, vortexed gently and incubated at $56^{\circ} \mathrm{C}$ for $3 \mathrm{hr}$. After precipitation and purification, we eluted DNA in $35 \mu \mathrm{l}$ molecular grade water and stored it at $-20^{\circ} \mathrm{C}$ prior to sequencing. It is likely that different pitcher plants captured different volumes of invertebrate contents in this study, which could influence the final results of the community composition analysis. It was impossible for us to standardize these volumes because the contents of a pitcher plant are highly degraded and mixed with varying amounts of organic matter, which is impossible to separate from the invertebrate contents. Moreover, standardization could mask natural variation in what the pitcher plants capture. For this reason, we chose to take an "eDNA" approach to extracting DNA from the pitchers, by soaking the entire contents in the buffers of the first stage of the DNA extraction.

We PCR amplified a 157-bp fragment of the cytochrome $c$ oxidase subunit 1 (COI) region using primers ZBJ-ArtF1c and ZBJArtR2c (Zeale, Butlin, Barker, Lees, \& Jones, 2011), modified using adaptors for the IonTorrent platform (Clare, Symondson, \& Fenton, 2014). Our PCR protocols were modelled on Bohmann et al. (2011). Our PCR was conducted in a $20-\mu \mathrm{l}$ reaction of $10 \mu \mathrm{l}$ of Qiagen multiplex PCR master mix (Qiagen, CA), $6 \mu \mathrm{l}$ of water, $1 \mu \mathrm{l}$ of each $10 \mu \mathrm{M}$ primer and $2 \mu \mathrm{l}$ of DNA. The thermocycler reaction was as follows: $95^{\circ} \mathrm{C}, 15 \mathrm{~min} ; 50$ cycles of $95^{\circ} \mathrm{C}, 30 \mathrm{~s}, 52^{\circ} \mathrm{C}, 30 \mathrm{~s}, 72^{\circ} \mathrm{C}, 30 \mathrm{~s}, 72^{\circ} \mathrm{C}$, $10 \mathrm{~min}$. We visualized our amplicons on a $2 \%$ agarose 96 -well precast E-gel (Invitrogen, Life Technologies) and performed size selection using the PCRClean DX kit (Aline Biosciences). We eluted the product in molecular grade water and measured the concentration on the QUBIT 2.0 spectrophotometer using a Qubit dsDNA HS Assay Kit (Invitrogen, Life Technologies). We performed high-throughput sequencing (HTS) on the lon Torrent (Life Technologies) sequencing platform using a 316 chip following the manufacturer's guidelines but with a $2 \times$ dilution. All PCR and sequencing steps were completed at the Biodiversity Institute of Ontario, Guelph, Canada.

Following Brown et al., 2014, Clare, Symondson, Broders et al., 2014 and Clare, Symondson, Fenton et al., 2014, MID sequences were used on both forward and reverse primers (dual indexing) allowing us to uniquely tag all samples while reducing primer costs. We assigned each sample a unique primer combination, so all sequences could be identified to original samples.

\section{3 | Bioinformatic analysis}

We cleaned and filtered sequences using Galaxy (Blankenberg et al., 2010; Giardine, Riemer, \& Hardison, 2005; Goecks, Nekrutenko, \& Taylor, 2010). We demultiplexed the reads using forward and reverse MID combinations, and we removed primers, MIDs, and adaptors, and collapsed sequences to unique haplotypes. We filtered reads by length, retaining only those that were 151-163 bp (the target amplicon is $157 \mathrm{bp}$ ). Using custom bash scripts, we removed haplotypes containing only one copy (singletons): a common practice which reduces the probability of including false positives from sequencing errors (Alberdi, Aizpurua, Gilbert, \& Bohmann, 2017). We then processed our sequence data in two different workflows to both quantify biodiversity (with clustered мотU data) and also to investigate whether we could assign species-level taxonomic identity (with BLAST searches on the unclustered raw haplotypes).

We clustered the sequences into MOтU at $92 \%$ similarity using QIIME (Caporaso et al., 2010) and picked a consensus sequence from each моти using the pick_otu and uclust functions. We selected a clustering level that generated the minimum amount of apparent underestimating or overestimating of species diversity (e.g., when two MOTU received the same assignment in BLAST/MEGAN, the data were considered "oversplit"). As with Salinas-Ramos, Herrera Montalvo, León-Regagnon, Arrizabalaga-Escudero, \& Clare, 2015 (another study on invertebrates using the same primer pair), we found the best results for мотU delimitation were obtained at the $92 \%$ similarity value. We screened for MOTu based on chimeras using the MOTHUR pipeline (Schloss et al., 2009). To assign taxonomic information to each мотU, we ran a BLAST search against an in-house database originating from $>600,000 \mathrm{COI}$ sequences downloaded from the NCBI database. We then used MEGAN version 5.10.7 (Huson, Auch, Qi, \& Schuster, 2007) to visualize this taxonomic information using the following lowest common ancestor (LCA) parameters: Min score $=150.1$, Max expected $=0.001$, Top per cent $=10.0$, Min support $=1$, LCA per cent $=100.0$, Min complexity $=0.2$.

\subsection{Ecological analysis}

We organized our data as MOTU presence/absence within each sample and then as frequencies of motus detected across all the sampling units (pitchers) for that elevation. For example, if моти $X$ was 
found in 10 of 40 pitchers in a site, it had an incidence of 0.25 . Pitchers were used as the sample units for calculating all species richness and diversity estimates, and rarefaction curves. All analyses were completed in $\mathrm{R}$ (version 3.3.0; R Development Core Team 2016).

\subsection{1 | MOTU richness and diversity}

We visualized мотU richness rarefaction curves for each elevation using incidence frequency data in INEXT (version 2.0.12; Hsieh, Ma, \& Chao, 2016a,b). Chao and Jost (2012) found that rarefaction/extrapolation by sample completeness rather than sample size gives rise to meaningful comparisons between communities and also ranks them more efficiently. They recommend rarefying or extrapolating based on the minimum sample coverage obtained with double the reference sample size (Chao \& Jost, 2012). We therefore examined мотU richness using rarefaction and extrapolation based on sample coverage of 0.679 (the minimum sample coverage obtained with double our sample size). We used the point estimation function in INEXT to calculate $84 \%$ confidence intervals for these richness estimates based on Hill numbers. While intuitively a $95 \%$ confidence interval would be equivalent to $5 \%$ Type 1 error, simulation studies demonstrate that in reality, an $84 \%$ confidence interval is more likely to reflect this error, and that a $95 \%$ confidence interval is overly conservative (MacGregor-Fors \& Payton, 2013; Payton, Greenstone, \& Schenker, 2003). This is used in other empirical papers and reviews on species richness estimates (for example, Gotelli \& Colwell 2011; Whitworth, Villacampa, Serrano Rojas, Downie, \& MacLeod, 2017).

We calculated the exponential Shannon diversity $(q=1)$ and inverse Simpson concentration $(q=2)$ for each site using the same sample coverage of 0.679 , as above, using SPADER (version 0.1.1; Chao, Ma, \& Hsieh, 2015). We presented results using effective numbers of species (i.e., Hill numbers $q=0, q=1$ and $q=2$ ), following Whitworth et al. (2017), because this allows meaningful comparison of estimates (Chao \& Jost, 2012). Chiu, Jost, and Chao (2014) recommend reporting the diversity for all species $(q=0)$, "typical" species $(q=1)$ and dominant species $(q=2)$.

We tested for a possible monotonic trend in per pitcher мотU richness using a linear mixed model implemented in the Ime4 package in R (Bates, Maechler, Bolker, \& Walker, 2015). Per pitcher мотU richness was coded as the response variable, elevation was coded as a continuous fixed effect predictor, and site was included as a random effect to take into account the site-based structure of our experimental design. For both this model and the ANOVA below, мотU richness was positively skewed, so we applied a square-root transformation to this variable. We coded an additional model without elevation as the fixed effect and compared the two models using AIC to examine the explanatory power of the elevation term. We did not consider the explanatory term of elevation to contribute to the model if the models did not differ from each other by more than two AIC points.

Because a monotonic linear trend is not the only biologically plausible ecological scenario to describe how мотU richness varies amongst different elevations (see discussion in Rahbek, 2005), we also conducted an ANOVA on per pitcher MOTU richness with site coded as an explanatory factor. This addresses the general question of whether differences in мотU richness are greater between sites than they are within sites.

\subsubsection{Community composition}

MOTU which MEGAN could not assign were removed from the data set. We used the taxonomic assignments from MEGAN to perform simple calculations of the frequency of each order across the entire data set (the number of taxa from a given order expressed as a proportion of the total number of taxa from all orders). We then graphically examined community composition by calculating the proportion of each order present at each site (the proportion of pitchers the MOTU is found in expressed as the total number of pitchers at that elevation).

To further probe the contents of each pitcher and to try to assign species-level identifications to sequences, we performed a BLAST search of all unclustered sequences against this database. We then extracted all results with $99 \%$ and $100 \%$ identity to a reference sequence, with bit scores $\geq 250$ and with no gaps using a custom built python script. We used European and worldwide biodiversity databases to check the geographic distributions of each species match obtained, including BOLD (Ratnasingham \& Hebert, 2007, 2013), PESI (2017), GBIF.org (2017), and ITIS (2017). In the rare cases where location could not be determined by these databases, we performed literature searches using Web of Science.

We assessed the correlation between community distance and elevational distance using the MOTU to which MEGAN had assigned taxonomy. We implemented this analysis using a partial Mantel test (Smouse, Long, \& Sokal, 1986) performed using the "VEGAN" package in R (Oksanen et al., 2016). We tested the binary Jaccard community dissimilarity matrix of MOTU per pitcher against a dissimilarity matrix of elevation. The format of the partial Mantel test allows us to control for a third dissimilarity matrix of geographic variables. This was necessary because some sites were not geographically evenly distributed-some sites which were further in terms of elevational distance were closer together geographically. We calculated a partial Mantel R statistic based on a Pearson's product-moment correlation (recommended by the "VEGAN" documentation) using 999 permutations to detect the correlation between community dissimilarity and environmental dissimilarity (in this case, elevation).

\section{3 | RESULTS}

\section{1 | Bioinformatic analysis}

We sequenced the contents of 193 Sarracenia purpurea pitchers across the five sites in France and Switzerland (Figure 1a and b). After demultiplexing and collapse to unique haplotypes, each pitcher contained an average of $3023 \pm 1,880$ haplotypes (mean $\pm S D$ ). On average, haplotypes were $152 \mathrm{bp}$ long, ranging in length from 15 to 
(a)

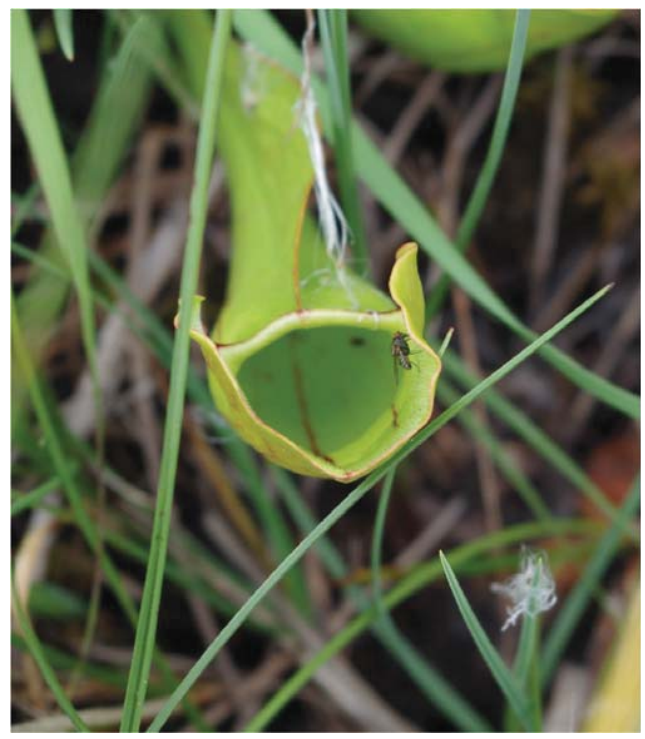

(b)

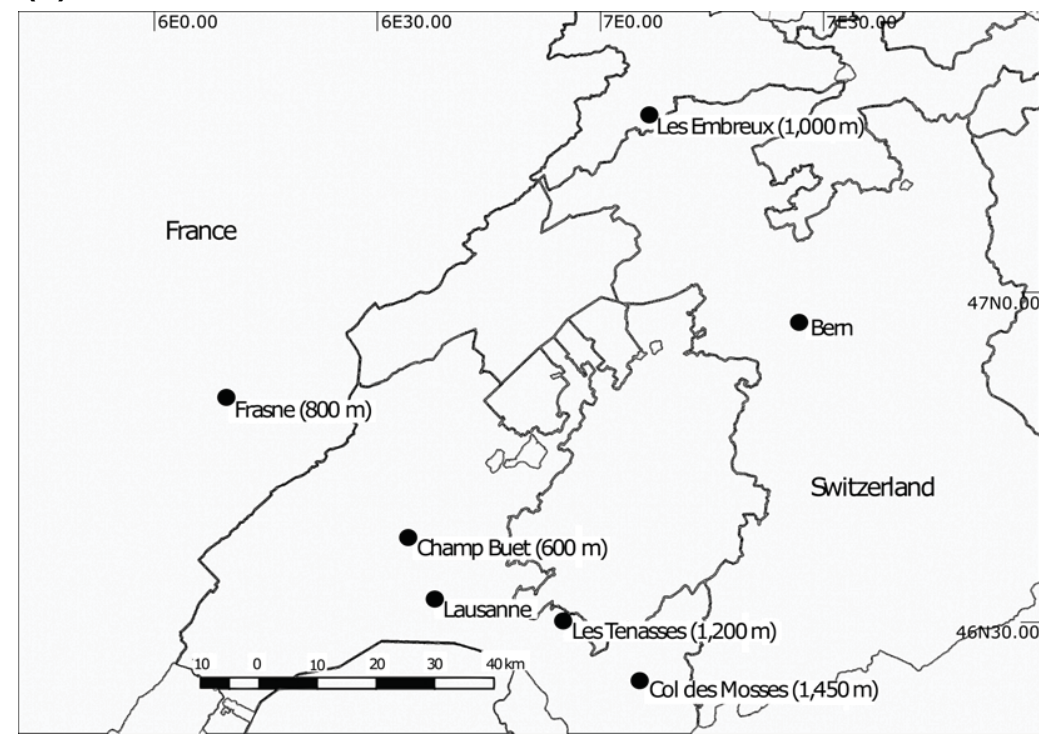

FIGURE 1 (a) Sarracenia purpurea with possible invertebrate prey at the lowest elevation (600 m) (photo credit: Axel Zander). (b) Locations of the sampling sites in the Swiss Alps and France

TABLE 1 Total and per pitcher sequence numbers for each stage of bioinformatics analysis using lon Torrent data

\begin{tabular}{|llc|}
\hline & Total & $\begin{array}{l}\text { Per pitcher } \\
\text { mean } \pm \text { SD }\end{array}$ \\
\hline After demultiplexing & $2,820,108$ & $14,612 \pm 7,463$ \\
\hline $\begin{array}{l}\text { After collapse to unique } \\
\text { haplotypes }\end{array}$ & 583,520 & $3,023 \pm 1,880$ \\
\hline After length filtering & 507,846 & $2,631 \pm 1,986$ \\
\hline After singleton removal & 107,907 & $583 \pm 393$ \\
\hline
\end{tabular}

$243 \mathrm{bp}$. We removed 75,674 haplotypes (13.0\%) during length filtering. $78.8 \%$ of length-filtered haplotypes were singletons and were also removed. For 13 samples, once all steps had been completed, the file was empty and was therefore removed from the analysis. All bioinformatics statistics are summarized in Table 1.

\subsection{Ecological analysis}

After clustering, we found 843 unique MOтU across all sites using a 92\% моти delimitation criteria. Of these, 11 were removed as probable chimeras. After visualization of taxonomic information in MEGAN, 1 моти was identified as an "environmental sample" (most likely a bacterial or fungal sequence) and therefore removed from further statistical analysis. Each pitcher contained an average of 17.4 мотU, but the distribution of мотU within pitchers was uneven, ranging from 0 (nо мотU assigned as per above) to 66 per pitcher. Each мотU appeared an average of 3.8 times over the entire study, but the frequencies of мотU were also highly variable, ranging from 1 to 83 occurrences within pitchers over the entire study; 437 мотU appeared just once across the study, indicating the presence of many rare MотU.

\subsection{1 | мотU richness and diversity}

Table 2 presents elevation measures of MOTU richness and diversity using Hill numbers $q=0,1$ and 2 (the effective мотU numbers corresponding to exponential Shannon and inverse Simpson concentration) using моти rarefied or extrapolated to even sample coverage (Figure 2).

Our results from the linear mixed model indicate that we found no monotonic directional trend in per pitcher мотU richness (Model 1 (including elevation as a continuous factor) AIC: 681.53, Model 2 (without elevation) AIC: 682.11). The difference in AIC between the two models was not greater than 2 (a difference greater than 2 is commonly taken to indicate significant explanatory power for a term present in one model but absent from the other). We tested sitespecific differences in MOTU richness with an ANOVA, which was nonsignificant (Figure 3, $F_{4,175}=1.34, p=0.257$ ). See Supporting information Table S2 for a full table of all statistical results.

\subsubsection{Community composition}

Two hundred and nineteen MOTU were unassigned by MEGAN and therefore removed for community composition analysis, leaving 612 unique мотU. Each pitcher had an average of 2.67 unassigned моти, and unassigned моти ranged from 1 to 34 occurrences in the entire data set. Diptera represented the most dominant order at all five elevations (Figure 4). Of the ten most common мотU across the study, eight were identified as Diptera. Following Diptera (48.7\% of unique incidences in the study), MOTU were most commonly assigned to Lepidoptera $(10.6 \%)$ and Coleoptera $(4.6 \%)$ at the order level.

The results of the partial Mantel test were significant $(r=0.059$, $p=0.023$ ), although the effect is small, as indicated by the low $r$ value. This indicates that only a small proportion of the variance in 
TABLE 2 Per site species richness and diversity indices based on data rarefied/extrapolated to a sample size coverage of 0.679, calculated with the INEXT package in $\mathrm{R}$

\begin{tabular}{|c|c|c|c|c|c|}
\hline Altitude $(\mathrm{m})$ & 600 & 800 & 1,000 & 1,200 & 1,450 \\
\hline Rarefied/extrapolated sample size, based on even sample coverage (0.679) & 32 & 36 & 28 & 44 & 44 \\
\hline Method & Rarefaction & Extrapolation & Rarefaction & Extrapolation & Extrapolation \\
\hline MOTU richness $(q=0)$ & 299.2 & 282.4 & 273.8 & 323.2 & 363.8 \\
\hline Exponential Shannon diversity $(q=1)$ & 206.0 & 197.3 & 194.4 & 225.0 & 246.5 \\
\hline Inverse Simpson concentration $(q=2)$ & 129.4 & 126.2 & 129.5 & 145.5 & 155.4 \\
\hline
\end{tabular}

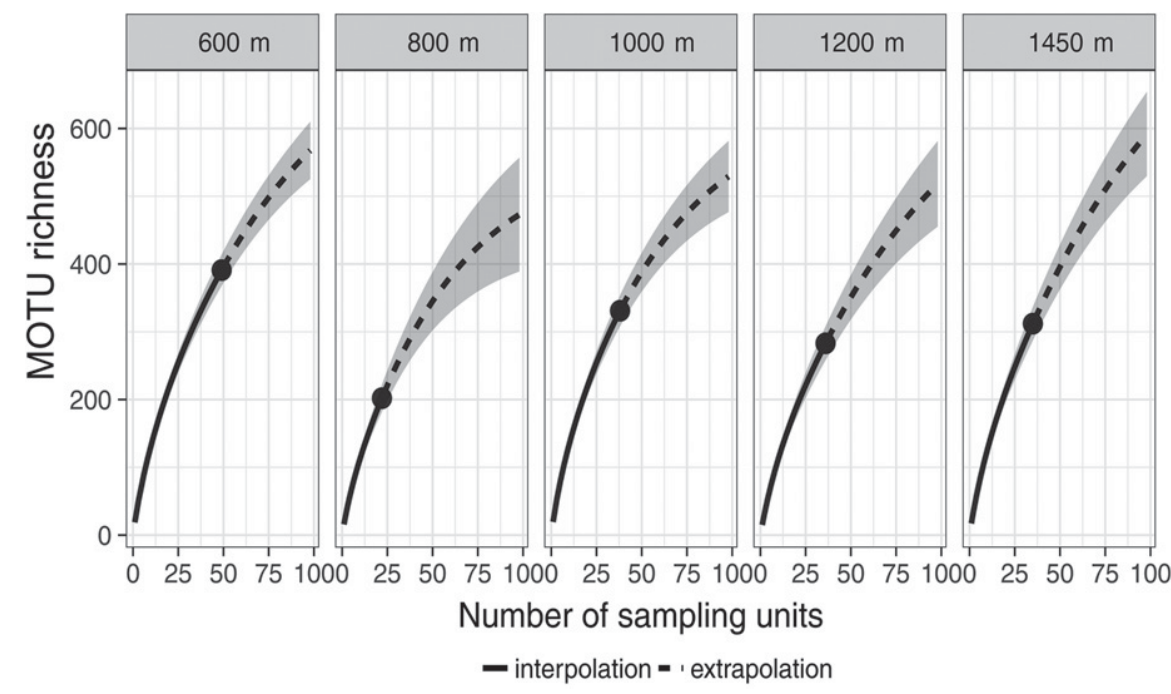

FIGURE 2 INEXT species accumulation curves using incidence frequency data and created using the INEXT package in R. Curves have been extrapolated to an endpoint of 102 (double the sample size) with 500 bootstrap replications

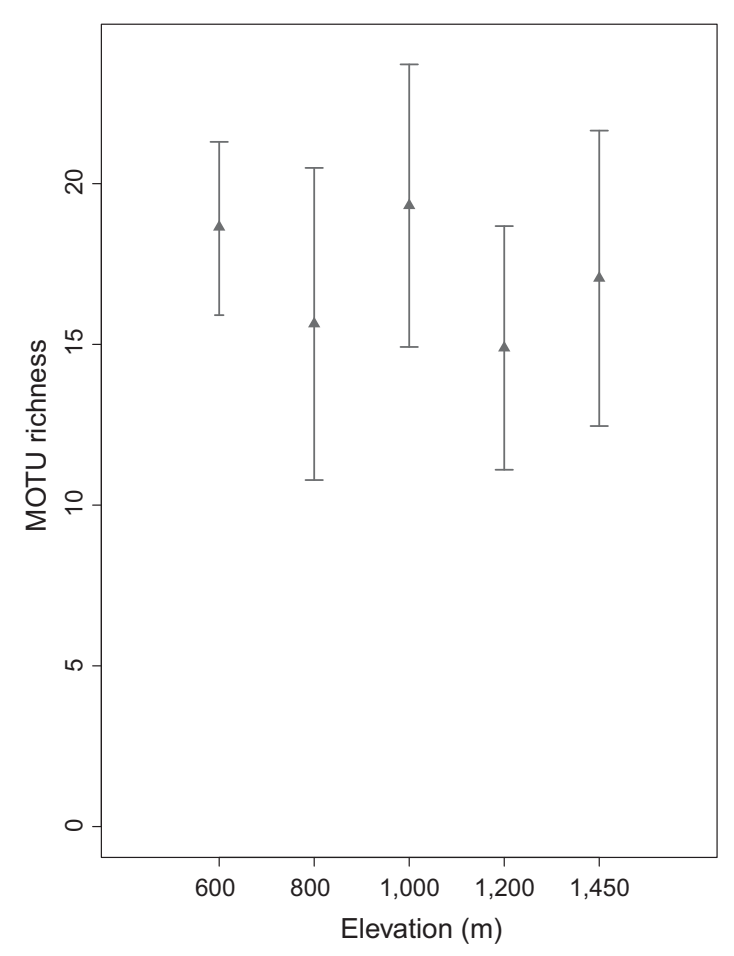

FIGURE 3 Per pitcher MOTU richness at each site elevation. Error bars are $95 \%$ confidence intervals community compositional similarity is explained by dissimilarity in site altitude, having controlled for any effect of geographic separation.

We also examined top BLAST hits at the $99 \%$ and $100 \%$ sequence similarity without clustering into MOTU in order to obtain possible genus and species-level identifications. A full list of best BLAST assignments is presented in Supporting information Table S3. We obtained 162 matches with high similarity to known species and for which we could confirm a west European distribution covering the study area. Similar to the мотU analysis, Diptera represented the highest proportion of hits recovered (65\%), followed by Lepidoptera (20\%) and Hymenoptera (3.7\%). Matches also included four species of beetle, two species of spiders, two rotifers and two millipedes. Many of the Diptera were represented by families such as the Sarcophagidae (flesh flies), Calliphoridae (blow flies) and Culicidae (mosquitoes). Sequences appearing in over 30 pitchers across the entire study matched to reference sequences from Sarcophaga carnaria, Sarcophaga jeanleclercqi, Sarcophaga lehmanni, Sarcophaga pyrenaica, Sarcophaga subvicina, Sarcophaga variegata, Polietes lardarius and Drosophila suzukii.

\section{4 | DISCUSSION}

The application of ecological analyses such as assessments of richness, diversity and community similarity to eukaryotic metabarcoding 


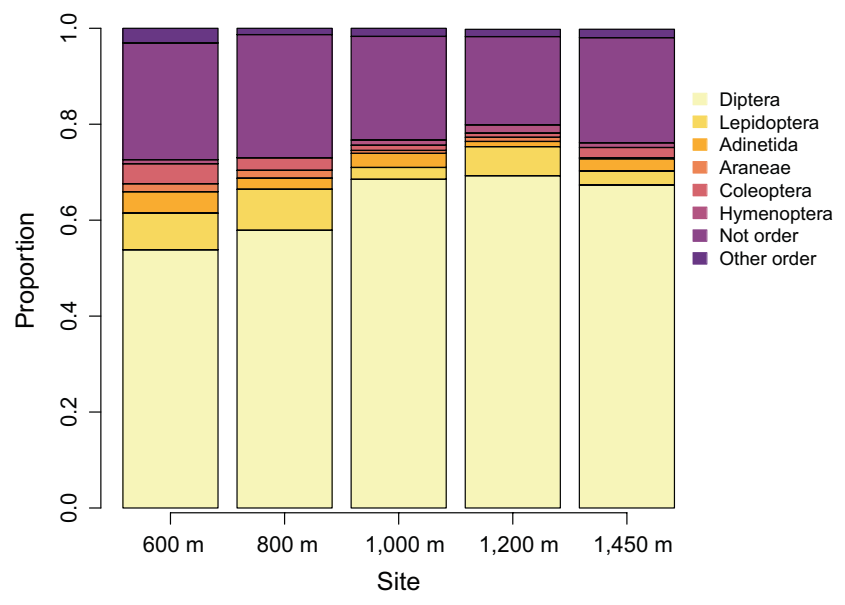

FIGURE 4 Proportions of orders found within the contents of Sarracenia purpurea at each elevation, using assignment of taxonomic information in MEGAN for MOTU. The six most common orders are displayed here. "Not order" indicates that taxonomic information was assigned higher than order level (e.g., class), and "Other order" indicates the small proportion of other, less common, orders found

data is a relatively recent analytical advance (Willerslev et al., 2014). Here, we use these analyses to explore the contents of allochthonous pitcher plant populations over an $850 \mathrm{~m}$ elevation gradient. We detect мотU which we were able to assign to a range of invertebrate taxa, and found that Diptera are the most frequently detected arthropod order, followed by Lepidoptera and Coleoptera. We were also able to match sequences directly against a reference database and obtained species-specific hits which were consistent with possible pitcher plant prey, pollinators and inquilines. Community similarity was linked to changes in elevation; however, this effect was small. We found no monotonic directional trend in per pitcher мотU richness with increasing elevation, nor did we find site-specific differences in MOTU richness. The advantages of DNA metabarcoding for resolving the taxonomy of partially digested material are clear: in this study and elsewhere (Bittleston, Baker, Strominger, Pringle, \& Pierce, 2016; Satler, Zellmer, \& Carstens, 2016), we were able to rapidly assess the contents of many pitchers, even when morphological analysis was difficult due to a loss of identifying features in the process of digestion by the carnivorous plant.

\section{1 | Contents of pitchers identified by metabarcoding}

Our results identified members of the Diptera, Coleoptera, Hymenoptera, Hemiptera and Lepidoptera orders, which are similarly found in morphological studies and in the native populations in North America (Table 3). By far the most species-rich order that we identified was Diptera, which was found widely across all sites. This result is consistent with previous morphological studies in North America (Cresswell, 1991), and Europe (PhD thesis: Zander, 2017). Dipteran мотU most likely represents prey items, but in North America midge and fly larvae also appear as keystone predators in the food web of pitcher plants (Cochran-Stafira \& Von Ende, 1998; Heard, 1994). The mosquito larva Wyeomyia smithii (the keystone predator in North American S. purpurea) is not distributed in central Europe (Adlassnig, Peroutka, \& Lendl, 2011; Gebühr, Pohlon, Schmidt, \& Küsel, 2006), although other members of the Culicidae family appear in our results. While Adlassnig et al. (2010) detected Sarcophagidae larvae inside European populations of congeneric Sarracenia flava; other researchers did not find arthropod inquilines living inside the pitchers during their studies (Gebühr et al., 2006; Zander, Bersier, \& Gray, 2017; Zander et al., 2016). The presence of insect inquilines, which are able to leave the pitcher after metamorphosis, seems to be unresolved in the European populations. A final possible source of Dipteran DNA could be from the pollinators of S. purpurea (Jürgens, Sciligo, Witt, El-Sayed, \& Suckling, 2012), as it is possible that our metabarcoding approach detects Dipteran DNA which has been transferred during these visits. Although the particular inquiline and prey species differ between native and allochthonous populations, invertebrate functional groups may be important biological predictors of pitcher plant range, as inquiline successional stages are thought to be similar in pattern (Gray, Akob, Green, \& Kostka, 2012; Zander et al., 2016).

We did not detect high numbers of ants, despite the fact that these are frequently found as prey in studies of North American plants (Newell \& Nastase, 1998), and that ant species richness is high in both Switzerland and France (175 and 172 species respectively: http:// www.antwiki.org/wiki/). Few studies exist of prey capture by the European populations of S. purpurea, but two counted the Formicidae family amongst its prey (Adlassnig et al., 2010, PhD thesis: Zander, 2017), although the former study also highlighted the generally low species richness of prey caught by these allochthonous populations of S. purpurea. Hymenoptera species which were detected belong to the sawfly, wasp and parasitic wasp groups. We matched 13 MOTU to the order Adinetida, which includes rotifers that participate in the S. purpurea food web by feeding on bacteria. However, if rotifers die within the pitcher, they will be digested as well, and DNA detection could result from these dead rotifers. Fifteen MOTU were matched to the Araneae order, which could be due to spiders sealing pitchers with their webs (Cresswell, 1991) in order to predate on insects, or appearing as pitcher plant prey themselves (Ellison \& Gotelli, 2009).

TABLE 3 Typical contents of a Sarracenia purpurea pitcher plant found in native ranges in North America

\begin{tabular}{|c|c|c|c|}
\hline & $\begin{array}{l}\text { Heard, } 1998 \text { ( } 260 \\
\text { pitchers over } \\
2 \text { years in one } \\
\text { bog, } \\
\text { Newfoundland, } \\
\text { CA) }\end{array}$ & $\begin{array}{l}\text { Cresswell, } 1991 \\
\text { ( } 214 \text { pitchers } \\
\text { over } 55 \text { days in } \\
\text { one bog, } \\
\text { Brighton, } \\
\text { Michigan) }\end{array}$ & $\begin{array}{l}\text { Judd, } 1959 \\
\text { ( } 489 \text { pitchers } \\
\text { over } 2 \text { years in } \\
\text { Byron bog, SW } \\
\text { Ontario) }\end{array}$ \\
\hline Hymenoptera & $33 \%$ & $9.7 \%$ & $11 \%$ \\
\hline Diptera & $33 \%$ & $71 \%$ & $63 \%$ \\
\hline Gastropoda & $8 \%$ & & \\
\hline Coleoptera & $7 \%$ & $5.5 \%$ & $14 \%$ \\
\hline Collembola & & $7.3 \%$ & \\
\hline Lepidoptera & & & $2 \%$ \\
\hline Araneida & & & $2 \%$ \\
\hline
\end{tabular}




\subsection{Effects of elevation}

Interestingly, we did not find evidence to support a decrease in the MOTU richness of pitcher plant contents at high elevations, but instead found no trend. It is possible that our sampling strategy did not cover a sufficiently large gradient to make a change in мотU richness detectable. For example, Rahbek, 2005 reported that patterns of species richness changed depending on the length of the sampled gradient and grain size (scale of analysis). More drastic changes in pitcher contents in our analysis could be expected at the timberline and snowline in the Alps (Meyer \& Thaler, 1995), but plant distribution (and therefore our sampling) is limited by the existence of boglike habitats for the plants. Due to the distribution of pitcher plants in discrete bog habitats, it was difficult to sample the plants on a continuous elevational gradient and examine directional trends in this way. We were additionally constrained by the limited number of sites available for study, which would make only the strongest directional effects detectable. We therefore also chose to include one test which did not directly interrogate a directional gradient in мотU richness (ANOVA), but found no additional site-specific differences in мотU richness. Alternatively, it may be possible that pitcher plant contents do not mirror external invertebrate richness but are controlled by other processes which act as a buffer between external invertebrate richness and the contents of the plant. Care was taken to select pitchers of a similar age and size, but other plant-specific factors might be at play, such as capture efficiency of prey.

We found a small but significant positive correlation between distance matrices of community composition and elevation. Previous studies of invertebrate fauna in the Alps have found changes in community composition at higher elevations, for example, reports of an increase in the proportion of Diptera relative to other orders (Pape et al., 2015), and a decrease in the species richness of wild bees (Hoiss, Krauss, Potts, Roberts, \& Steffan-Dewenter, 2012). Studies to date have been based on populations of free-living invertebrates, whereas here we examined the contents of a carnivorous plant. It would take further work to investigate whether the contents of plants reflects external invertebrate diversity. The lack of change in MOTU richness and small change in invertebrate community composition does suggest that the contents of $S$. purpurea are reasonably homogenous throughout the sites we studied. Given that at least some of this detritus will be digested and form a nitrogen source for the plant, it appears that $S$. purpurea is able to obtain an adequate diet to establish non-native populations even at elevations as high as $1450 \mathrm{~m}$, which has implications for its spread and establishment around non-native Europe, and possibly to more northern parts of Europe during regional warming.

\subsection{Molecular and bioinformatic methods}

We recovered a short target fragment length (157 bp) to maximize recovery in a system where DNA might be degraded by enzymes or the food web within S. purpurea. Primer and reference library selection plays an important role in taxonomic recovery in DNA metabarcoding studies. A related study targeted the contents of a congeneric pitcher plant with a different target region, the large subunit 28 S rRNA region (Satler et al., 2016). The authors recovered many more fungal sequences, with arthropods making up a smaller proportion of recovered hits than in our study, alongside protozoans and annelids. However, we used a primer originally designed specifically for studies on degraded invertebrate matter, in conjunction with a local reference library composed of majority invertebrate reference sequences, and thus, the difference is not surprising. We performed two analyses with our sequences. First, we assigned all sequences to мотU with only ordinal-level identifications, and second, we compared sequences to a known database to retrieve any species-level identifications. The first analysis is used as a statistical method to compare the levels of richness and diversity at the ordinal level but should not be conflated with taxonomic assignment (see a discussion in Clare et al., 2016). Different bioinformatic parameters used to define моти can produce extensive variation in мотU estimates, although this is unlikely to strongly influence ecological analyses (Clare et al., 2016). For this reason, we have used a low clustering threshold (92\%) to minimize the generation of false OTUs rather than to recover a particular taxonomic rank. In the second analysis, we identify species through comparison to our known reference database. Reference collections for invertebrates even in Europe are still largely incomplete, and most reference collections contain a bias towards species of charismatic or economic interest and some species still remain undescribed. For example, a sampling campaign involving the collection of Diptera specimens in the north east of Italy found 10 species new to science (Ziegler, 2012). Because of this, we have not performed an ecological analysis of these data assigned at species level, but present these simply as species that are likely present in the pitchers.

\subsection{DNA degradation and the use of metabarcoding}

Little is known about how the processes of decomposition or digestion affect the detection of DNA, and how long the DNA of invertebrate prey remains in the pitcher after decomposition. In freshwater systems, the persistence of eDNA in water has been estimated not to exceed 25 days (see discussion in Turner, Uy, \& Everhart, 2015), with degradation likely to occur through exposure to abiotic factors such as UV components of light. There are some studies, which detect DNA for much longer lengths, for example, 132 days in lake sediments (Turner et al., 2015), 88 days in spider webs (Xu, Yen, Bowman, \& Turner, 2015), and of course DNA can be extracted from sediment cores that are much older (Willerslev et al., 2014). Fewer studies relate to how digestion affects prey DNA within animals (and no studies exist for carnivorous plants), but Wallinger et al. (2015) showed that DNA persisted in the gut of carabid beetles for at least $72 \mathrm{hr}$ after feeding (the maximum time point measured in their experiment) and that the persistence of DNA after digestion was likely to be prey species-specific. Complex and unpredictable processes associated with digestion and 
degradation will influence detection of species, estimates of MOTU and subsequent ecological analyses in metabarcoding studies of diet. The fact that DNA is likely to persist for some time, and originate from multiple sources (e.g., prey, inquilines, pollinators, traces of eDNA in this study), could blur the strict relationship between species presence and species detection, given its persistence in the environment. However, DNA-based techniques will be informative in providing medium- to long-term estimates of dietary contents if DNA persists inside the digestive parts. The use of environmental RNA is also likely to be of interest in the study of pitcher plants due to its shorter half-life (Littlefair \& Clare, 2016; Pochon, Zaiko, Fletcher, Laroche, \& Wood, 2017), which could possibly discriminate between dead prey and living inquilines in a study such as this. Pitcher plants represent an ideal system to test this in, because their passive feeding strategies can be more easily manipulated than that of active predatory animals.

\section{5 | CONCLUSIONS}

We used metabarcoding techniques to elucidate the contents of allochthonous populations of the pitcher plant Sarracenia purpurea along an elevational gradient. Molecular techniques have rarely been applied to carnivorous plants, but were instrumental in this study in determining the richness of invertebrate мотU, as well as matching to species-level sequences against a reference database. We found no evidence for a directional trend or site-specific differences in мотU richness, but did see small but significant changes in the community composition of the pitcher. Metabarcoding can be usefully applied to future carnivorous plant studies, as partially degraded invertebrate prey exoskeletons present a particular challenge for morphological identification. Although limited to bog habitats, $S$. pupurea appears to be obtaining similar pitcher contents compared to North American populations (Cresswell, 1991; Heard, 1998; Judd, 1959), even at high altitudes, indicating that European populations appear well established, with implications for the invasion biology of carnivorous plants.

\section{ACKNOWLEDGEMENTS}

We thank David Bennett and Dr Monika Struebig for assistance with DNA extractions and data analysis. We further thank Manuela Schwarz for help collecting the field samples and Louis-Félix Bersier for funding the sample collection (Swiss National Science Foundation Grant awarded to Louis-Félix Bersier Nr. 31003A_138489). We thank Brock Fenton for reading an earlier draft, and the two reviewers and editor for their comments which substantially improved the manuscript.

\section{AUTHOR CONTRIBUTIONS}

B.C. and A.Z. conceived and designed the study, A.Z. collected the field samples, B.C. contributed reagents/sequencing, J.L. and C.D.S.C. performed the laboratory work, J.L. analysed the data and made the figures, and J.L. wrote the study with assistance from B.C. and the other co-authors.

\section{DATA ACCESSIBILITY}

Representative sequences for MOTU in each pitcher (grouped by elevation) and a summary matrix of MOTus in each plant are provided in Dryad https://doi.org/10.5061/dryad.tg8fq3c.

\section{ORCID}

Joanne E. Littlefair (D) http://orcid.org/0000-0002-4481-0211 Elizabeth L. Clare (iD) http://orcid.org/0000-0002-6563-3365

\section{REFERENCES}

Adlassnig, W., Mayer, E., Peroutka, M., Pois, W., \& Lichtsheidl, I. K. (2010). Two American sarracenia species as neophyta in central Europe. Phyton; Annales Rei Botanicae, 49, 279-292.

Adlassnig, W., Peroutka, M., \& Lendl, T. (2011). Traps of carnivorous pitcher plants as a habitat: Composition of the fluid, biodiversity and mutualistic activities. Annals of Botany, 107, 181-194. https://doi. org/10.1093/aob/mcq238

Alberdi, A., Aizpurua, O., Gilbert, M. T. P., \& Bohmann, K. (2017). Scrutinizing key steps for reliable metabarcoding of environmental samples. Methods in Ecology and Evolution, 9(1), 1-14.

Bates, D., Maechler, M., Bolker, B., \& Walker, S. (2015). Fitting linear mixed-effects models using Ime4. Journal of Statistical Software, 67, 1-48.

Bittleston, L. S., Baker, C. C. M., Strominger, L. B., Pringle, A., \& Pierce, N. E. (2016). Metabarcoding as a tool for investigating arthropod diversity in Nepenthes pitcher plants. Austral Ecology, 41, 120-132. https://doi.org/10.1111/aec.12271

Blankenberg, D., Kuster, G. V., Coraor, N., Ananda, G., Lazarus, R., Mangan, M., ... Taylor, J. (2010). NIT 19.10 Galaxy: A web-based genome analysis tool for experimentalists. Current Protocols in Molecular Biology, 19, 1-21.

Blumthaler, M. (2012). Solar radiation of the high Alps. In C. Lütz (Ed.), Plants in alpine regions: Cell physiology of adaption and survival strategies (pp. 1-27). New York, NY: Springer Wein.

Bohmann, K., Monadjem, A., Lehmkuhl Noer, C., Rasmussen, M., Zeale, M. R. K., Clare, E., ... Gilbert, M. T. P. (2011). Molecular diet analysis of two African free-tailed bats (Molossidae) using high throughput sequencing. PLoS One, 6, e21441. https://doi.org/10.1371/journal. pone.0021441

Brown, D. S., Symondson, W. O. C., Burger, R., Cole, N., Vencatasamy, D., Clare, E. L., ... Symondson, W. O. C. (2014). Dietary competition between the alien Asian Musk Shrew (Suncus murinus) and a reintroduced population of Telfair's Skink (Leiolopisma telfairii). Molecular Ecology, 23, 3695-3705. https://doi.org/10.1111/mec. 12445

Caporaso, J. G., Kuczynski, J., Stombaugh, J., Bittinger, K., Bushman, F. D., Costello, E. K., ... Knight, R. (2010). QIIME allows analysis of highthroughput community sequencing data. Nature Methods, 7, 335336. https://doi.org/10.1038/nmeth.f.303

Case, T. J., Holt, R. D., Mcpeek, M. A., \& Keitt, T. H. (2005). The community context of species' borders: Ecological and evolutionary perspectives. Oikos, 108, 28-46. https://doi.org/10.1111/j.0030-1299.2005. 13148.x 
Chao, A., \& Jost, L. (2012). Coverage-based rarefaction and extrapolation: Standardizing samples by completeness rather than size. Ecology, 93, 2533-2547. https://doi.org/10.1890/11-1952.1

Chao, A., Ma, K. H., \& Hsieh, T. C. (2015). SPAder: Species Prediction and Diversity Estimation with R. R package version 0.1.0.

Chiu, C.-H., Jost, L., \& Chao, A. (2014). Phylogenetic beta diversity, similarity, and differentiation measures based on Hill numbers. Ecological Monographs, 84, 21-44. https://doi.org/10.1890/12-0960.1

Clare, E. L. (2014). Molecular detection of trophic interactions: Emerging trends, distinct advantages, significant considerations and conservation applications. Evolutionary Applications, 7, 1144-1157. https://doi. org/10.1111/eva.12225

Clare, E. L., Chain, F. J. J., Littlefair, J. E., \& Cristescu, M. E. (2016). The effects of parameter choice on defining molecular operational taxonomic units and resulting ecological analyses of metabarcoding data. Genome, 59, 981-990. https://doi.org/10.1139/gen-20150184

Clare, E. L., Symondson, W. O. C., Broders, H., Fabianek, F., Fraser, E. E., MacKenzie, A., ... Reimer, J. P. (2014). The diet of Myotis lucifugus across Canada: Assessing foraging quality and diet variability. Molecular Ecology, 23, 3618-3632. https://doi.org/10.1111/mec.12542

Clare, E. L., Symondson, W. O. C., \& Fenton, M. B. (2014). An inordinate fondness for beetles? Variation in seasonal dietary preferences of night-roosting big brown bats (Eptesicus fuscus). Molecular Ecology, 23, 3633-3647. https://doi.org/10.1111/mec.12519

Cochran-Stafira, D. L., \& Von Ende, C. N. (1998). Integrating bacteria into food webs: Studies with Sarracenia purpurea inquilines. Ecology, 79, 880-898. https://doi.org/10.2307/176587

Colwell, R. K., Brehm, G., Cardelus, C. L., Gilman, A. C., \& Longino, J. T. (2008). Global warming, elevational range shifts, and lowland biotic attrition in the wet tropics. Science, 322, 258-261. https://doi.org/ 10.1126/science.1162547

Cresswell, J. C. (1991). Capture rates and composition of insect prey of the pitcher plant Sarracenia purpurea. The American Midland Naturalist, 125, 1-9. https://doi.org/10.2307/2426363

Desmarais, K. H., \& Tessier, A. J. (1999). Performance trade-off across a natural resource gradient. Oecologia, 120, 137-146. https://doi.org/ $10.1007 / \mathrm{s} 004420050842$

Ellison, A. M., \& Gotelli, N. J. (2009). Energetics and the evolution of carnivorous plants - Darwin's "most wonderful plants in the world". Journal of Experimental Botany, 60, 19-42. https://doi.org/10.1093/ jxb/ern179

Fick, S. E., \& Hijmans, R. J. (2017). Worldclim 2: New 1-km spatial resolution climate surfaces for global land areas. International Journal of Climatology, 37, 4302-4315. https://doi.org/10.1002/joc.5086

Flesch, A. D., \& Steidl, R. J. (2010). Importance of environmental and spatial gradients on patterns and consequences of resource selection. Ecological Applications, 20, 1021-1039. https://doi.org/10.1890/090076.1

Floyd, R., Abebe, E., Papert, A., \& Blaxter, M. (2002). Molecular barcodes for soil nematode identification. Molecular Ecology, 11, 839 850.

Fukami, T., \& Wardle, D. A. (2005). Long-term ecological dynamics: Reciprocal insights from natural and anthropogenic gradients. Proceedings of the Royal Society B: Biological Sciences, 272, 2105-2115. https://doi.org/10.1098/rspb.2005.3277

Gallien, L., Mazel, F., Lavergne, S., Renaud, J., Douzet, R., \& Thuiller, W. (2015). Contrasting the effects of environment, dispersal and biotic interactions to explain the distribution of invasive plants in alpine communities. Biological Invasions, 17, 1407-1423. https://doi.org/10. 1007/s10530-014-0803-1

GBIF.org (2017). GBIF home page. Retrieved from: https://www.gbif.org [Last accessed 1 June 2017].

Gebühr, C., Pohlon, E., Schmidt, A. R., \& Küsel, K. (2006). Development of microalgae communities in the phytotelmata of allochthonous populations of Sarracenia purpurea (Sarraceniaceae). Plant Biology, 8, 849-860. https://doi.org/10.1055/s-2006-924474

Giardine, B., Riemer, C., \& Hardison, R. (2005). Galaxy: A platform for interactive large-scale genome analysis. Genome Research, 15, 14511455. https://doi.org/10.1101/gr.4086505

Goecks, J., Nekrutenko, A., \& Taylor, J. (2010). Galaxy: A comprehensive approach for supporting accessible, reproducible, and transparent computational research in the life sciences. Genome Biology, 11, R86. https://doi.org/10.1186/gb-2010-11-8-r86

Gotelli, N. J., \& Colwell, R. K. (2011). Estimating species richness. In A. E. Magurran, \& B. J. McGill (Eds.), Biological diversity: Frontiers in measurement and assessment (pp. 39-54). Oxford, UK: Oxford University Press.

Gray, S. M., Akob, D. M., Green, S. J., \& Kostka, J. E. (2012). The bacterial composition within the Sarracenia purpurea model system: Local scale differences and the relationship with the other members of the food web. PLoS One, 7, e50969. https://doi.org/10.1371/journal.pone. 0050969

Greig, H. S., Wissinger, S. A., \& Mcintosh, A. R. (2013). Top-down control of prey increases with drying disturbance in ponds: A consequence of non-consumptive interactions? Journal of Animal Ecology, 82, 598607. https://doi.org/10.1111/1365-2656.12042

Heard, S. B. (1994). Pitcher-plant midges and mosquitoes: A processing chain commensalism. Ecology, 75, 1647-1660. https://doi.org/10. 2307/1939625

Heard, S. B. (1998). Capture rates of invertebrate prey by the pitcher plant, Sarracenia purpurea L. The American Midland Naturalist, 139, 79-89. https://doi.org/10.1674/0003-0031(1998)139[0079:CROIPB] 2.0.CO;2

Hodkinson, I. D. (2005). Terrestrial insects along elevation gradients: Species and community responses to altitude. Biological Reviews, 80, 489-513. https://doi.org/10.1017/S1464793105006767

Hoiss, B., Krauss, J., Potts, S. G., Roberts, S., \& Steffan-Dewenter, I. (2012). Altitude acts as an environmental filter on phylogenetic composition, traits and diversity in bee communities. Proceedings of the Royal Society B: Biological Sciences, 279, 4447-4456. https://doi.org/ 10.1098/rspb.2012.1581

Horner, J. D., Steele, J. C., Underwood, C. A., \& Lingamfelter, D. (2012). Age-related changes in characteristics and prey capture of seasonal cohorts of Sarracenia alata pitchers. The American Midland Naturalist, 167, 13-27. https://doi.org/10.1674/0003-0031-167.1.13

Hsieh, T. C., Ma, K. H., \& Chao, A. (2016a). INEXT: An R package for rarefaction and extrapolation of species diversity (Hill numbers). Methods in Ecology and Evolution, 7, 1451-1456. https://doi.org/10.1111/ 2041-210X.12613

Hsieh, T. C., Ma, K. H., \& Chao, A. (2016b) INEXT: iNterpolation and EXTrapolation for species diversity. Retrieved from http://chao.stat. nthu.edu.tw/wordpress/software_download/

Huson, D., Auch, A., Qi, J., \& Schuster, S. (2007). MEGAN analysis of metagenomic data. Genome Research, 17, 377-386. https://doi.org/ 10.1101/gr.5969107

ITIS. (2017). Integrated taxonomic information system. Retrieved from the Integrated Taxonomic Information System on-line database, http:// www.itis.gov. [last accessed 01 June 2017]

Jones, R., Baltz, D., \& Allen, R. (2002). Patterns of resource use by fishes and macroinvertebrates in Barataria Bay, Louisiana. Marine Ecology Progress Series, 237, 271-289. https://doi.org/10.3354/meps237271

Judd, W. W. (1959). Studies of the byron bog in southwestern Ontario $X$. Inquilines and victims of the pitcher-plant Sarracenia purpurea $L$. The Canadian Entomologist, 91, 171-180. https://doi.org/10.4039/ Ent91171-3

Jürgens, A., Sciligo, A., Witt, T., El-Sayed, A. M., \& Suckling, D. M. (2012). Pollinator-prey conflict in carnivorous plants. Biological Reviews, 87, 602-615. https://doi.org/10.1111/j.1469-185X.2011. 00213.x 
Kitching, R. L. (2000). Food webs and container habitats: The natural history and ecology of phytotelmata. Cambridge: Cambridge University Press. https://doi.org/10.1017/CBO9780511542107

Kneitel, J. M., \& Miller, T. E. (2002). Resource and top-predator regulation in the pitcher plant (Sarracenia Purpurea) inquiline community. Ecology, 83, 680-688. https://doi.org/10.1890/0012-9658(2002)083 [0680:RATPRI]2.0.CO;2

Lester, R. E., Close, P. G., Barton, J. L., Pope, A. J., \& Brown, S. C. (2014). Predicting the likely response of data-poor ecosystems to climate change using space-for-time substitution across domains. Global Change Biology, 20, 3471-3481. https://doi.org/10.1111/gcb. 12634

Littlefair, J. E., \& Clare, E. L. (2016). Barcoding the food chain: Sanger to high-throughput sequencing. Genome, 59, 946-958. https://doi.org/ 10.1139/gen-2016-0028

MacGregor-Fors, I., \& Payton, M. E. (2013). Contrasting diversity values: Statistical inferences based on overlapping confidence intervals. PLoS One, 8, 8-11.

Meyer, E., \& Thaler, K. (1995). Animal diversity at high altitudes in the Austrian central alps. In F. S. Chapin, \& C. Körner (Eds.), Arctic and alpine biodiversity: Patterns, causes and ecosystem consequences (pp. 97-108). Berlin, Heidelberg: Springer-Verlag.

Newell, S., \& Nastase, A. (1998). Efficiency of insect capture by Sarracenia purpurea (Sarraceniaceae), the Northern Pitcher Plant. American Journal of Botany, 85, 88-91. https://doi.org/10.2307/2446558

O'Gorman, E. J., Pichler, D. E., Adams, G., Benstead, J. P., Cohen, H., Craig, N., \& Woodward, G. (2012). Impacts of warming on the structure and functioning of aquatic communities: Individual-to ecosystem-level responses. Advances in Ecological Research, 47, 81-176.

Oksanen, J., Blanchet, F. G., Friendly, M., Kindt, R., Legendre, P., McGlinn, D., ... Helene, W. (2016). veGAN: Community ecology package. $R$ package version 2.4-0. Retrieved from https://CRAN.R-project.org/packa ge=vegan

Pape, T., Beuk, P., Pont, A., Shatalkin, A. I., Ozerov, A. L., Woźnica, A J., ... de Jong, Y. (2015). Fauna Europaea: Diptera - Brachycera. Biodiversity Data Journal, 3, e4187. https://doi.org/10.3897/BDJ.3.e 4187

Parmesan, C. (2006). Ecological and evolutionary responses to recent climate change. Annual Review of Ecology, Evolution, and Systematics, 37, 637-669. https://doi.org/10.1146/annurev.ecolsys.37.091305. 110100

Payton, M. E., Greenstone, M. H., \& Schenker, N. (2003). Overlapping confidence intervals or standard error intervals: What do they mean in terms of statistical significance? Journal of Insect Science, 3, 15841249

PESI. (2017). Pan-European Species directories Infrastructure. Retrieved from www.eu-nomen.eu/portal [Last accessed on 01 June 2017]

Pochon, X., Zaiko, A., Fletcher, L. M., Laroche, O., \& Wood, S. A. (2017). Wanted dead or alive? Using metabarcoding of environmental DNA and RNA to distinguish living assemblages for biosecurity applications. PLoS One, 12, 1-19.

Pompanon, F., Deagle, B. E., Symondson, W. O. C., Brown, D. S., Jarman, S. N., \& Taberlet, P. (2012). Who is eating what: Diet assessment using next generation sequencing. Molecular Ecology, 21, 1931-1950. https://doi.org/10.1111/j.1365-294X.2011.05403.x

R Development Core Team (2016) R: A language and environment for statistical computing. Vienna, Austria: R Foundation for Statistical Computing. http://www.R-project.org/.

Rahbek, C. (2005). The role of spatial scale and the perception of largescale species-richness patterns. Ecology Letters, 8, 224-239.

Ratnasingham, S., \& Hebert, P. D. N. (2007). BOLD: The barcode of life data system (www.barcodinglife.org) . Molecular Ecology Notes, 7, 355-364.

Ratnasingham, S., \& Hebert, P. D. N. (2013). A DNA-based registry for all animal species: The barcode index number (BIN) system.
PLoS One, 8, e66213. https://doi.org/10.1371/journal.pone. 0066213

Salinas-Ramos, V. B., Herrera Montalvo, L. G., León-Regagnon, V., Arrizabalaga-Escudero, A., \& Clare, E. L. (2015). Dietary overlap and seasonality in three species of mormoopid bats from a tropical dry forest. Molecular Ecology, 24, 5296-5307. https://doi.org/10.1111/ mec.13386

Satler, J. D., Zellmer, A. J., \& Carstens, B. C. (2016). Biogeographic barriers drive co-diversification within associated eukaryotes of the Sarracenia alata pitcher plant system. PeerJ, 4, e1576. https://doi.org/ 10.7717/peerj.1576

Schloss, P. D., Westcott, S. L., Ryabin, T., Hall, J. R., Hartmann, M., Hollister, E. B., ... Weber, C. F. (2009). Introducing mothur: Open-source, platform-independent, community-supported software for describing and comparing microbial communities. Applied and Environmental Microbiology, 75, 7537-7541. https://doi.org/10.1128/AEM.0154109

Smouse, P., Long, J., \& Sokal, R. (1986). Multiple regression and correlation extensions of the Mantel test of matrix correspondence. Systematic Zoology, 35, 627-632. https://doi.org/10.2307/2413122

Sundqvist, M. K., Sanders, N. J., \& Wardle, D. A. (2013). Community and ecosystem responses to elevational gradients: Processes, mechanisms, and insights for global change. Annual Review of Ecology, Evolution, and Systematics, 44, 261-280. https://doi.org/10.1146/an nurev-ecolsys-110512-135750

Turner, C. R., Uy, K. L., \& Everhart, R. C. (2015). Fish environmental DNA is more concentrated in aquatic sediments than surface water. Biological Conservation, 183, 93-102. https://doi.org/10.1016/j.biocon. 2014.11.017

Valentini, A., Miquel, C., Nawaz, M. A., Bellemain, E., Coissac, E., Pompanon, F., ... Taberlet, P. (2009). ew perspectives in diet analysis based on DNA barcoding and parallel pyrosequencing: The trnL approach. Molecular Ecology Resources, 9, 51-60. https://doi.org/10. 1111/j.1755-0998.2008.02352.x

Walker, K. J. (2014). Sarracenia purpurea subsp purpurea (Sarraceniaceae) naturalised in Britain and Ireland: Distribution, ecology, impacts and control. New Journal of Botany, 4, 33-41. https://doi.org/10.1179/ 2042349714Y.0000000035

Wallinger, C., Sint, D., Baier, F., Schmid, C., Mayer, R., \& Traugott, M. (2015). Detection of seed DNA in regurgitates of granivorous carabid beetles. Bulletin of Entomological Research, 105, 728-735. https://doi. org/10.1017/S000748531500067X

Whitworth, A., Villacampa, J., Serrano Rojas, S. J., Downie, R., \& MacLeod, R. (2017). Methods matter: Different biodiversity survey methodologies identify contrasting biodiversity patterns in a human modified rainforest - A case study with amphibians. Ecological Indicators, 72, 821-832. https://doi.org/10.1016/j.ecolind.2016.08.055

Willerslev, E., Davison, J., Moora, M., Zobel, M., Coissac, E., Edwards, M. E., ... Taberlet, P. (2014). Fifty thousand years of Arctic vegetation and megafaunal diet. Nature, 506, 47-51. https://doi.org/10. 1038/nature12921

Xu, C. C. Y., Yen, I. J., Bowman, D., \& Turner, C. R. (2015). Spider web DNA: A new spin on noninvasive genetics of predator and prey. PLoS One, 10, e0142503. https://doi.org/10.1371/journal.pone.0142503

Zamora, R., Gomez, J. M., \& Hodar, J. A. (1997). Responses of a carnivorous plant to prey and inorganic nutrients in a Mediterranean environment. Oecologia, 111, 443-451. https://doi.org/10.1007/ s004420050257

Zander, A. (2017) Interactions of Sarracenia purpurea and its inquilines; comparing Europe and North America. PhD thesis, University of Fribourg, Fribourg.

Zander, A., Bersier, L.-F., \& Gray, S. M. (2017). Effects of temperature variability on community structure in a natural microbial food web. Global Change Biology, 23, 56-67. https://doi.org/10.1111/gcb. 13374 
Zander, A., Gravel, D., Bersier, L.-F., \& Gray, S. M. (2016). Top predators affect the composition of naive protist communities, but only in their early-successional stage. Oecologia, 180, 519-528. https://doi.org/10. 1007/s00442-015-3476-2

Zeale, M. R. K., Butlin, R. K., Barker, G. L. A., Lees, D. C., \& Jones, G. (2011). Taxon-specific PCR for DNA barcoding arthropod prey in bat faeces. Molecular Ecology Resources, 11, 236-244. https://doi.org/10. 1111/j.1755-0998.2010.02920.x

Ziegler, J. (2012). The biodiversity of a Central Alpine landscape as exemplified by the two-winged flies (Diptera). In Mitteilungen der Deutschen Gesellschaft für allgemeine und angewandte Entomologie (vol. 18 pp. 45-49), Vorträge der Entomologentagung in Berlin, Germany, 21-24 March 2011. Munich, Germany: Deutsche Gesellschaft für allgemeine und angewandte Entomologie e.V.

\section{SUPPORTING INFORMATION}

Additional supporting information may be found online in the Supporting Information section at the end of the article. 